\title{
Evaluation of Antibacterial Enrofloxacin in Eggs by Matrix Solid Phase Dispersion-Flow Injection Chemiluminescence
}

\author{
Xiaocui Duan, ${ }^{1}$ Pingping Zhang, ${ }^{2}$ Jing Feng, ${ }^{3}$ and Ning Jiao ${ }^{4}$ \\ ${ }^{1}$ Hebei Key Lab of Laboratory Animal Department of Genetics, Hebei Medical University, Shijiazhuang 050017, China \\ ${ }^{2}$ Institute of Basic Medicine, Hebei Medical University, Shijiazhuang 050017, China \\ ${ }^{3}$ Hebei Chemical and Pharmaceutical Vocational Technology College, Shijiazhuang 050031, China \\ ${ }^{4}$ Pharmaceutical Preparation Section of the Third Hospital of Hebei Medical University, Shijiazhuang 050051, China
}

Correspondence should be addressed to Ning Jiao; jiao_ning@126.com

Received 13 September 2013; Revised 21 February 2014; Accepted 23 February 2014; Published 30 March 2014

Academic Editor: Patricia Valentao

Copyright (C) 2014 Xiaocui Duan et al. This is an open access article distributed under the Creative Commons Attribution License, which permits unrestricted use, distribution, and reproduction in any medium, provided the original work is properly cited.

\begin{abstract}
The study based on the chemiluminescence (CL) reaction of potassium ferricyanide and luminol in sodium hydroxide medium, enrofloxacin (ENRO) could dramatically enhance CL intensities and incorporated with matrix solid-phase dispersion (MSPD) technique (Florisil used as dispersant, dichloromethane eluted the target compounds). A simple flow injection chemiluminescence (FL-CL) method with MSPD technique for determination of ENRO in eggs was described. Under optimal conditions, the CL intensities were linearly related to ENRO concentration ranging from $4.0 \times 10^{-8}$ g. $\mathrm{L}^{-1}$ to $5.0 \times 10^{-5} \mathrm{~g} . \mathrm{L}^{-1}$, with a correlation coefficient of 0.9989 and detection limit of $5.0 \times 10^{-9}$ g. $\mathrm{L}^{-1}$. The relative standard deviation was $3.6 \%$ at an ENRO concentration of $2.0 \times$ $10^{-6}$ g. $\mathrm{L}^{-1}$. Our testing technique can help ensure food safety, and thus, protect public health.
\end{abstract}

\section{Introduction}

Bovine food quality has become a concern for consumers over the last decade. Food safety and public health have also become primary issues in policy making, retailer strategy, consumer concern, and producers themselves. Harmful compounds in food come from various sources, such as environmental pollution, food processing, and unreasonable use of medicine. Fluoroquinolone antibiotics have a wide range of antibacterial activities and have been used in veterinary medicine because of the effectiveness in treating bacterial infections [1] and the enhanced antibacterial activities against Gram-positive and Gram-negative organisms [2,3]. Enrofloxacin (ENRO) is a fluoroquinolone antibiotic that has been approved for use in food animals. This antibiotic is effective against organisms resistant to antibacterial substances used in veterinary medicine, such as $\beta$-lactam antibiotics, aminoglycosides, tetracyclines, and macrolides [4]. The use of ENRO in veterinary medicine is subject to regulation because its residues may persist in edible animal tissues and result in the development of drug-resistant bacterial strains or allergies. These residues and the metabolites in foods of animal origin are significant for consumer health and safety. The European community has fixed a maximum residue limit in edible animal products for ENRO that ranges from $100 \mu \mathrm{g} \cdot \mathrm{kg}^{-1}$ to $300 \mu \mathrm{g} \cdot \mathrm{kg}^{-1}$ [5]. Therefore, identifying the residue in meat and other animal products (e.g., milk, eggs) used for human consumption is important.

The analytical methods for ENRO are grouped into electrochemical analysis (EA) [6], capillary electrophoresis (CE) [7], and high-performance liquid chromatography (HPLC) [8]. However, the limitations of EA are poor stability and selectivity. CE and HPLC can separate and quantify different forms of ENRO and its derivations. These methods also have minimum interference from enzymes, but they entail expensive setup cost, as well as complex extraction and purification procedure.

Chemiluminescence (CL) is an interesting detection method because of the low detection limit, rapidity, wide linear working range, and simple instrumentation $[9,10]$; CL is more acceptable and applicable to analyze ENRO in samples with low residue count. The determination of 


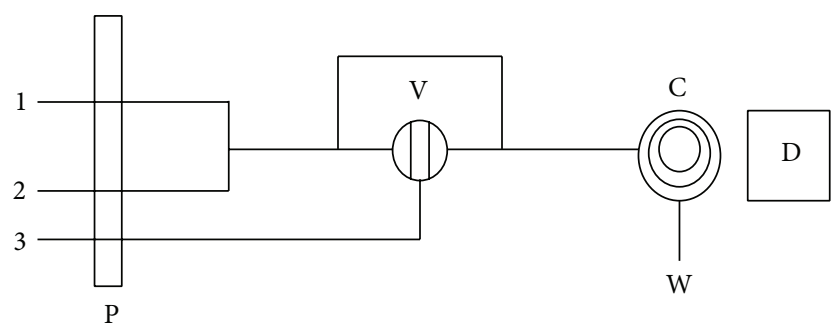

FIGURE 1: Schematic of flow injection chemiluminescence analysis. 1: Mixture of $\mathrm{NaOH}$ and luminol, 2: $\mathrm{K}_{3} \mathrm{Fe}(\mathrm{CN})_{6}$ solution, 3: ENRO solution, P: peristaltic pump, C: flow cell, V: injection valve, W: waste solution, and D: detector.

fluoroquinolone antibiotics in complex matrices, such as food, often requires reasonable sample extraction and preparation process prior to instrumental analysis. Matrix solidphase dispersion (MSPD) is an effective sample preparation technique first reported in 1989 by American professor Baker [11]. This technique has applications in analytical processes for the preparation, extraction, and fractionation of solid, semisolid, and/or highly viscous biological samples and food samples [12-14].

We found that a strong CL signal was emitted when a trace amount of ENRO was added to luminol-potassium ferricyanide solution, and its intensity was strongly dependent on the ENRO concentration. Based on this result, a rapid, sensitive, and inexpensive CL method with MSPD technique was proposed to determine the ENRO content. The effect of reaction conditions on the CL signal intensity was explored in the flow injection (FI) mode of analysis. Under the optimized conditions, the proposed MSPD-FI-CL system was applied for the determination of ENRO content in eggs.

\section{Experimental Section}

2.1. Reagents and Solutions. Luminol was obtained from Sigma-Aldrich (St. Louis, Mo, USA); $0.01 \mathrm{~mol} \cdot \mathrm{L}^{-1}$ of stock solution was prepared by dissolving $0.443 \mathrm{~g}$ luminol in $5.0 \mathrm{~mL}$ of $1 \mathrm{~mol} \cdot \mathrm{L}^{-1} \mathrm{NaOH}$, and the solution was transferred into a $250 \mathrm{~mL}$ volumetric flask and diluted with water. $\mathrm{K}_{3} \mathrm{Fe}(\mathrm{CN})_{6}$ was obtained from Beijing Chemical Reagent Company (Beijing, China), and $5.0 \times 10^{-2} \mathrm{~mol} \cdot \mathrm{L}^{-1}$ of its stock solution was prepared by dissolving $4.13 \mathrm{~g}$ protocatechuic aldehyde in $250 \mathrm{~mL}$ water. Acetonitrile, petroleum ether, methanol, $\mathrm{n}$-hexane, and dichloromethane were supplied either from Beijing Chemical Reagent Company (Beijing, China) or from Tianjin Chemical Reagent Company (Tianjin, China). Florisil (150-250 $\mu \mathrm{m})$ was obtained from Sinopharm Chemical Reagent Co., Ltd. (Shanghai, China). All reagents were of analytical grade and were used as received without further purification. Double distilled water (referred to as pure water hereafter) was used as a carrier flow and for the preparation of solutions. The diluted working solutions were prepared and used freshly and daily.

2.2. Apparatus. FI-CL was performed with an IFFL-D flow injection CL analysis system (Xi'an Ruike Electronic Equipment Corporation, Xian, China). Figure 1 shows

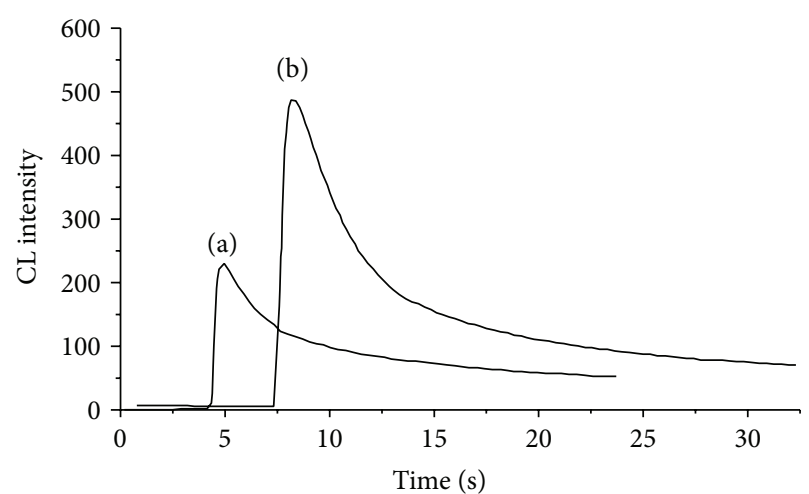

FIGURE 2: CL kinetic curve of the CL reaction. (a) $8.0 \times 10^{-5} \mathrm{~mol} \cdot \mathrm{L}^{-1}$ luminol $-4.0 \times 10^{-4} \mathrm{~mol} \cdot \mathrm{L}^{-1} \mathrm{~K}_{3} \mathrm{Fe}(\mathrm{CN})_{6}$ and (b) $8.0 \times 10^{-5} \mathrm{~mol} \cdot \mathrm{L}^{-1}$ luminol $-4.0 \times 10^{-4} \mathrm{~mol} \cdot \mathrm{L}^{-1} \mathrm{~K}_{3} \mathrm{Fe}(\mathrm{CN})_{6}-2.0 \times 10^{-6} \mathrm{~g} \cdot \mathrm{L}^{-1} \mathrm{ENRO}$.

the schematic diagram of the FI-CL analyzer that comprised two peristaltic pumps working at a constant rate of $40 \mathrm{rpm}$. One channel was used to carry $\mathrm{NaOH}$ and luminol solution, and the other was used to carry the $\mathrm{K}_{3} \mathrm{Fe}(\mathrm{CN})_{6}$ solution. The sample solutions were injected from a sample valve. The enhanced CL signals were produced immediately and were recorded. The flow cell was a $10 \mathrm{~cm}$ spiral glass tubing $(2.0 \mathrm{~mm}$ i.d.), and the distance between the injection valve and the flow cell was about $20 \mathrm{~cm}$.

2.3. Sample Preparation. The eggs were obtained from four different farm markets, and six eggs from each market were used for real sample analysis. Each egg yolk or white was separated, homogenized, and stored at $4^{\circ} \mathrm{C}$ for no longer than $24 \mathrm{~h}$ until analysis. Consequently, $0.5 \mathrm{~g}$ of egg yolk or white homogenate was accurately weighted into a $50 \mathrm{~mL}$ glass mortar. After weighing $1.0 \mathrm{~g}$ of Florisil $(1.5 \mathrm{~g}$ for the treated albumen sample) using a glass pestle until a homogeneous mixture was obtained, the homogenized sample was transferred and packed into a $10 \mathrm{~mL}$ glass syringe with a piece of filter paper on the bottom. Another filter paper was placed on the top of mixture and compressed using the syringe plunger. For the yolk sample, interfering compounds, such as lipids, were washed with $3 \mathrm{~mL}$ petroleum ether. The target component was eluted with $6 \mathrm{~mL}$ of dichloromethane by gravitation. The eluate was allowed to slowly drip into a $10 \mathrm{~mL}$ volumetric flask and was diluted with dichloromethane to the volume. Two milliliters of the solution was transferred from the volumetric flask into a graduated tube using a $0.45 \mu \mathrm{m}$ microvoid filter film. The solution was concentrated under a nitrogen stream for drying, and the residue was dissolved with $0.2 \mathrm{~mol} \cdot \mathrm{L}^{-1} \mathrm{NaOH}$ solution for the FI-CL analysis.

\section{Results and Discussion}

3.1. Characteristics of the CL Reaction. The kinetic curves of the CL reaction were tested with a static system using $8.0 \times$ $10^{-5} \mathrm{~mol} \cdot \mathrm{L}^{-1}$ luminol and $4.0 \times 10^{-4} \mathrm{~mol} \cdot \mathrm{L}^{-1} \mathrm{~K}_{3} \mathrm{Fe}(\mathrm{CN})_{6}$. The reaction rate in solution was rapid; the maximum intensity from reagent mixing took $3 \mathrm{~s}$, and the signal returned to zero for $20 \mathrm{~s}$ (Figure 2(a)). Figure 2(b) reveals that the CL intensity sharply increased in the presence of $2.0 \times 10^{-6} \mathrm{~g} \cdot \mathrm{L}^{-1}$ ENRO. 


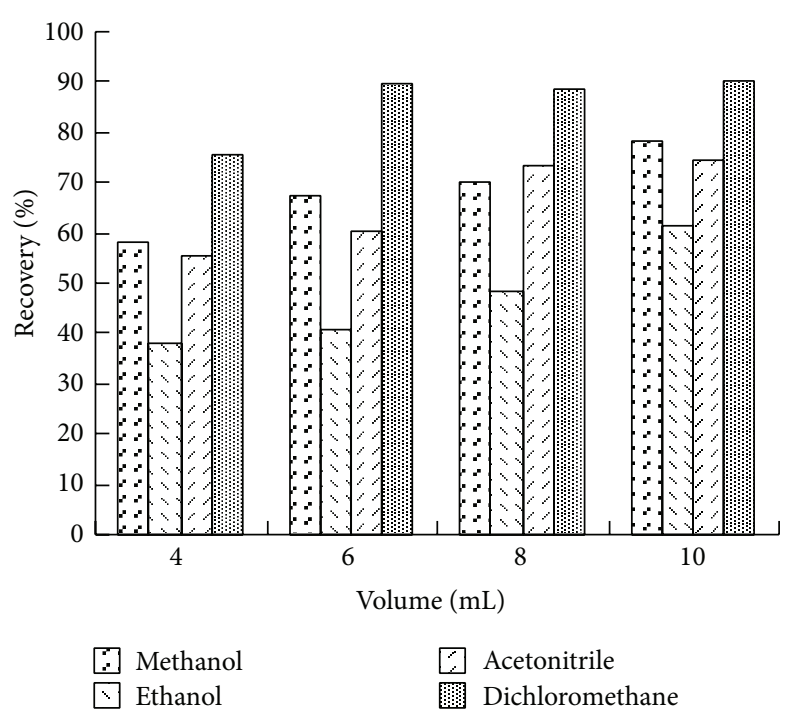

FIGURE 3: The effect of eluent on the recovery of ENRO in egg.

\subsection{Optimization of MSPD Extraction Conditions}

3.2.1. Dispersant Selection. The efficacy of the chromosorb, the neutral activated alumina, the acidic activated alumina, and Florisil as dispersants was analyzed. Following the treatment and CL analysis, the recovery rates were lower than $60 \%$ due to the interference of the impurities when chromosorb, neutral activated alumina, and acidic activated alumina were used as dispersants upon blending with the sample. The target compound had better elution efficacy, and the recovery was more than $85 \%$ when Florisil was used as the dispersant. The effect of sample ratio and Florisil was also investigated. The results showed that $1: 3$ was the best ratio for the egg sample treatment.

3.2.2. The Choice of Washing Solvents and Eluents. A washing step for the MSPD cartridge is necessary because of the high protein and lipid contents in eggs. The testing results showed that petroleum ether was better than n-hexane. Three milliliters of petroleum ether volume was optimal based on the results.

During elution, the selection of eluent can be critical in obtaining a satisfactory recovery of ENRO from the sample matrix. In this assay, different organic solvents were tested using methanol, ethanol, acetonitrile, and dichloromethane with volumes ranging from $4 \mathrm{~mL}$ to $10 \mathrm{~mL}$ with $2 \mathrm{~mL}$ increments (Figure 3). The results showed that the system using dichloromethane was significantly better than that obtained for compounds, and the complete elution of ENRO from the cartridge was obtained within $6 \mathrm{~mL}$ dichloromethane; this compound was selected as the eluent.

\subsection{Optimization of CL Conditions}

3.3.1. Effect of Carrier Flow. Carrier flows were tested at the following conditions: [ENRO] $=2.0 \times 10^{-6} \mathrm{~g} \cdot \mathrm{L}^{-1}$, [Luminol] $=8.0 \times 10^{-5} \mathrm{~mol} \cdot \mathrm{L}^{-1} ;\left[\mathrm{K}_{3} \mathrm{Fe}(\mathrm{CN})_{6}\right]=4.0 \times 10^{-4} \mathrm{~mol} \cdot \mathrm{L}^{-1}$.

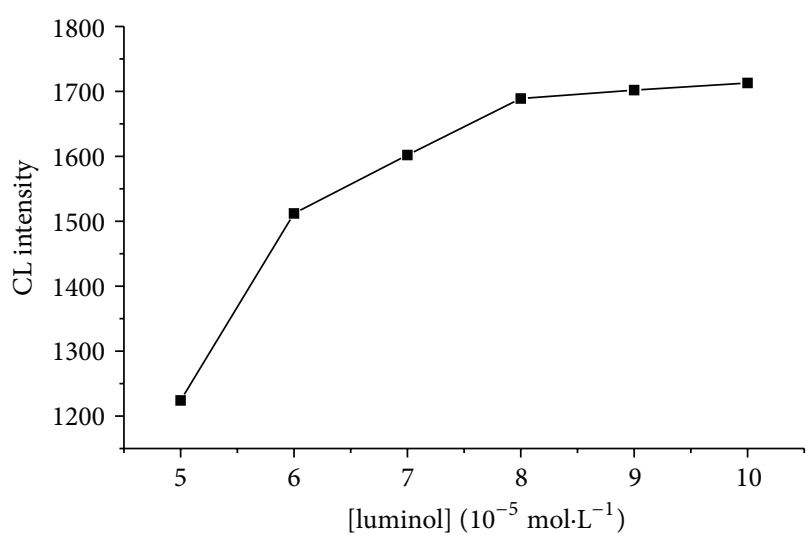

FIgURE 4: Effect of luminol concentration on CL intensity. Condition: $[\mathrm{ENRO}]=2.0 \times 10^{-6} \mathrm{~g} \cdot \mathrm{L}^{-1},\left[\mathrm{~K}_{3} \mathrm{Fe}(\mathrm{CN})_{6}\right]=4.0 \times 10^{-4} \mathrm{~mol} \cdot \mathrm{L}^{-1}$, luminol in $0.2 \mathrm{~mol} \cdot \mathrm{L}^{-1} \mathrm{NaOH}$ solution.

TABLE 1: Determination results of ENRO in eggs.

\begin{tabular}{cccccc}
\hline Samples & $\begin{array}{c}\text { Found } \\
\left(\mu \mathrm{g} \cdot \mathrm{g}^{-1}\right)\end{array}$ & $\begin{array}{c}\text { Added } \\
\left(\mu \mathrm{g} \cdot \mathrm{g}^{-1}\right)\end{array}$ & $\begin{array}{c}\text { Total found } \\
\left(\mu \mathrm{g} \cdot \mathrm{g}^{-1}\right)\end{array}$ & $\begin{array}{c}\text { Recovery } \\
(\%)\end{array}$ \\
\hline $\mathbf{1}$ & Egg yolk & - & & 0.0446 & 89.2 \\
& Egg white & - & & 0.0458 & 91.6 \\
$\mathbf{2}$ & Egg yolk & 0.0234 & & 0.0708 & 94.8 \\
& Egg white & 0.0522 & 0.0500 & 0.0985 & 92.6 \\
$\mathbf{3}$ & Egg yolk & - & & 0.0453 & 90.6 \\
& Egg white & 0.0258 & & 0.0701 & 88.6 \\
$\mathbf{4}$ & Egg yolk & - & & 0.0483 & 96.6 \\
& Egg white & - & & 0.0492 & 98.4 \\
\hline
\end{tabular}

The flow rates of $\mathrm{NaOH}$, borax, and phosphate buffer solutions were included. The experiments indicated that the CL emission intensity was the most sensitive in $\mathrm{NaOH}$ solution. The effect of $\mathrm{NaOH}$ concentration from $0.05 \mathrm{~mol} \cdot \mathrm{L}^{-1}$ to $0.5 \mathrm{~mol} \cdot \mathrm{L}^{-1}$ on $\mathrm{CL}$ emission intensities was further analyzed. Surprisingly, the use of $0.2 \mathrm{~mol} \cdot \mathrm{L}^{-1} \mathrm{NaOH}$ solution as a carrier flow yielded the best result; thus, we selected this solution as the carrier flow.

3.3.2. Effect of Concentration of Luminol on the CL Intensity. The effect of the concentration of luminol used in the reaction on the CL intensity was also studied. The CL emission intensity was enhanced with the increase in the luminol concentration, while keeping the concentration of alkalis and other reactants constant (Figure 4). On the other hand, the CL base signal generated by the reaction between $\mathrm{K}_{3} \mathrm{Fe}(\mathrm{CN})_{6}$ and luminol also increased. As a result, the signal-to-noise ratio $(\mathrm{S} / \mathrm{N})$ likewise increased. After the analysis of the baseline $\mathrm{S} / \mathrm{N}$ ratio and the sensitivity of the system, the best concentration of sodium sulfite was $8.0 \times 10^{-5} \mathrm{~mol} \cdot \mathrm{L}^{-1}$.

\subsubsection{Effect of $\mathrm{K}_{3} \mathrm{Fe}(\mathrm{CN})_{6}$ Concentration on the CL Intensity.} Figure 5 plots the $\mathrm{CL}$ intensities against $\mathrm{K}_{3} \mathrm{Fe}(\mathrm{CN})_{6}$ concentration while keeping the concentration of other reactants constant. The maximum CL intensity was obtained at the 
TABLE 2: Comparison of different methods for the determination of ENRO.

\begin{tabular}{lccccc}
\hline Method & IRPLC & SPE-HPLC & AdSV & CE & MSPD-FL-CL \\
\hline Sample & Drug & Milk & Urine & Muscle & Egg \\
LOD & $0.028 \mu \mathrm{g} \mathrm{mL}^{-1}$ & $2.20 \mu \mathrm{g} \mathrm{kg}^{-1}$ & $1.3 \mathrm{ng} \mathrm{mL}^{-1}$ & $10 \mu \mathrm{g} \mathrm{kg}^{-1}$ & $5.0 \times 10^{-9} \mathrm{~g} \cdot \mathrm{L}^{-1}$ \\
LR & $4.0-108 \mu \mathrm{g} \mathrm{mL}^{-1}$ & $10-50 \mu \mathrm{g} \mathrm{kg}^{-1}$ & $5-25 \mathrm{ng} \mathrm{mL}^{-1}$ & $10-300 \mu \mathrm{g} \mathrm{kg}^{-1}$ & $4.0 \times 10^{-8}-5.0 \times 10^{-5} \mathrm{~g} \cdot \mathrm{L}^{-1}$ \\
RSD (\%) & $0.21-0.50$ & $0.05-0.78$ & 1.7 & 4.38 & 3.6 \\
Recovery (\%) & $99.6-101.8$ & 96 & $95.4-115.2$ & 74 & $88.6-98.4$ \\
$r$ & 0.9999 & 0.9985 & 0.9899 & 0.9999 & 0.9989 \\
Reference & {$[1]$} & {$[15]$} & {$[16]$} & {$[7]$} & This work \\
\hline
\end{tabular}

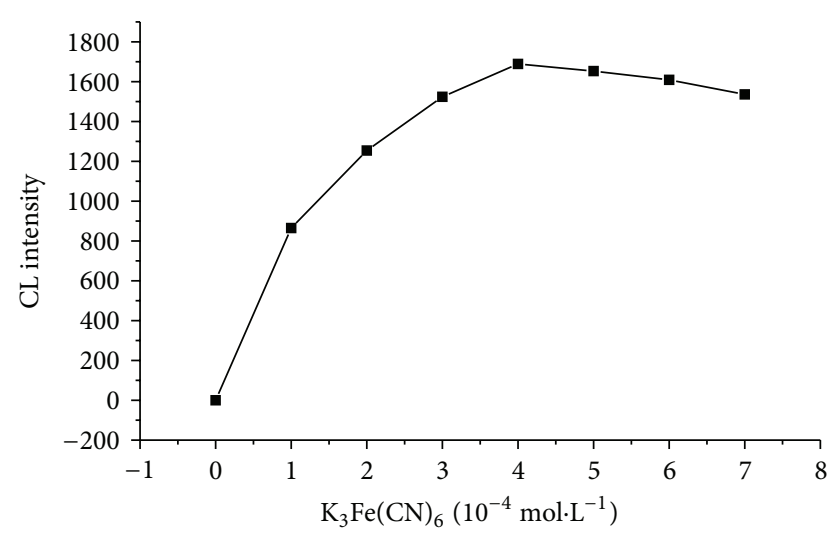

Figure 5: Effect of $\mathrm{K}_{3} \mathrm{Fe}(\mathrm{CN})_{6}$ concentration on CL intensity. Condition: $[$ ENRO $]=2.0 \times 10^{-6} \mathrm{~g} \cdot \mathrm{L}^{-1},[$ luminol $]=8.0 \times 10^{-5} \mathrm{~mol} \cdot \mathrm{L}^{-1}$, luminol in $0.2 \mathrm{~mol} \cdot \mathrm{L}^{-1} \mathrm{NaOH}$ solution.

optimal $\mathrm{K}_{3} \mathrm{Fe}(\mathrm{CN})_{6}$ concentration of $4.0 \times 10^{-4} \mathrm{~mol} \cdot \mathrm{L}^{-1}$. Above this concentration, CL intensity decreased because of the inner filter effect from the absorption of the CL emission by the high $\mathrm{K}_{3} \mathrm{Fe}(\mathrm{CN})_{6}$ concentration.

3.4. Analytical Characteristics for ENRO. For the assay calibration, the working solutions at seven ENRO concentration levels were prepared and extracted following the MSPD procedure. Under the optimal conditions, the calibration curve for the ENRO determination was obtained by plotting the CL signal against the ENRO concentration. The detection range was from $4.0 \times 10^{-8} \mathrm{~g} \cdot \mathrm{L}^{-1}$ to $5.0 \times 10^{-5} \mathrm{~g} \cdot \mathrm{L}^{-1}$, and the regression equation was given as

Intensity

$$
=189.13+75.24 c \quad\left(c=10^{-7} \mathrm{~g} \cdot \mathrm{L}^{-1}, r=0.9989\right) .
$$

The detection limit $(3 \sigma)$ for the regression equation was $5.0 \times$ $10^{-9} \mathrm{~g} \cdot \mathrm{L}^{-1}$, and the relative standard deviation (RSD; $n=13$ ) was $3.6 \%$ for $2.0 \times 10^{-6} \mathrm{~g} \cdot \mathrm{L}^{-1} \mathrm{ENRO}$.

3.5. Interference Study. In order to assess the possible analytical application of the proposed CL system to samples, the influences of some common inorganic ions and a couple of relevant organic compounds on CL intensities were investigated. A foreign material was considered not to interfere if it caused a relative error of less than $\pm 5 \%$ during the determination of $2.0 \times 10^{-6} \mathrm{~g} \cdot \mathrm{L}^{-1}$ ENRO. Results showed that the following substances did not interfere: 100 -fold $\mathrm{Na}^{+}, \mathrm{K}^{+}$, $\mathrm{Cl}^{-}, \mathrm{SO}_{4}{ }^{2-}$, and $\mathrm{NO}_{3}{ }^{-} ; 50$-fold $\mathrm{Mg}^{2+}, \mathrm{Ca}^{2+}$, and $\mathrm{Ba}^{2+} ; 20$-fold starch; glucose; and urea as well as 10 -fold glycine and tartaric acid.

3.6. Sample Analysis. Following the analytical procedure, the proposed method was applied to recover ENRO in eggs. The recovery experiment of standard addition was performed simultaneously. Table 1 lists the relevant data, with the recovery rates ranging from $88.6 \%$ to $98.4 \%$. Table 2 compares the obtained limit of detection, the relative standard deviation, the linear range, the recovery, and the correlation coefficient with those from ion pairing and reversed phase liquid chromatography [1], solid-phase extraction-HPLC [15], adsorptive stripping voltammetry [16], and CE [7]. The proposed method provides the similar extraction efficiency, whereas the detection limit of ENRO is lower than those from other methods.

\section{Conclusions}

ENRO greatly enhances the CL signal of potassium ferricyanide and luminol in $\mathrm{NaOH}$ medium. FI-CL with MSPD was developed to determine ENRO in eggs, which is sensitive, rapid, and simple, and did not require sophisticated reagents and equipment. The MSPD-FI-CL system yielded satisfactory results, which implies the efficacy in evaluating the ENRO content in other foods to assure food safety and to protect public health.

\section{Conflict of Interests}

The authors declare that there is no conflict of interests regarding the publication of this study.

\section{Acknowledgments}

This work was supported by State Administration of Traditional Medicine of Hebei Province (2012011) and the Construction Program of Hebei Scientific Condition (12966121D). 


\section{References}

[1] A. S. Amin, H. A. Dessouki, and I. A. Agwa, "Ion-pairing and reversed phase liquid chromatography for the determination of three different quinolones: enrofloxacin, lomefloxacin and ofloxacin," Arabian Journal of Chemistry, vol. 4, no. 3, pp. 249257, 2011.

[2] N. Chansiripornchai and J. Sasipreeyajan, "Efficacy of Sarafloxacin in broilers after experimental infection with Escherichia coli," Veterinary Research Communications, vol. 26, no. 4, pp. 255-262, 2002.

[3] V. Korten and B. E. Murray, "The nosocomial transmission of enterococci," Current Opinion in Infectious Diseases, vol. 6, no. 4, pp. 498-505, 1993.

[4] A. L. Cinquina, P. Roberti, L. Giannetti et al., "Determination of enrofloxacin and its metabolite ciprofloxacin in goat milk by high-performance liquid chromatography with diode-array detection: optimization and validation," Journal of Chromatography A, vol. 987, no. 1-2, pp. 221-226, 2003.

[5] A. A. Ensaifi, T. Khayamian, and M. Taei, "Determination of ultra trace amount of enrofloxacin by adsorptive cathodic stripping voltammetry using copper(II) as an intermediate," Talanta, vol. 78, no. 3, pp. 942-948, 2009.

[6] A. A. Ensaifi, M. Taei, T. Khayamian, and F. Hasanpour, "Simultaneous voltammetric determination of enrofloxacin and ciprofloxacin in urine and plasma using multiwall carbon nanotubes modified glassy carbon electrode by least-squares support vector machines," Analytical Science, vol. 26, pp. 803808, 2010.

[7] D. Barrón, E. Jiménez-Lozano, J. Cano, and J. Barbosa, "Determination of residues of enrofloxacin and its metabolite ciprofloxacin in biological materials by capillary electrophoresis," Journal of Chromatography B: Biomedical Sciences and Applications, vol. 759, no. 1, pp. 73-79, 2001.

[8] M. A. Bimazubute, E. Rozet, I. Dizier et al., "Liquid chromatographic determination of enrofloxacin in nasal secretions and plasma of healthy pigs using restricted access material for online sample clean-up," Journal of Chromatography A, vol. 1189, no. 1-2, pp. 456-466, 2008.

[9] L. Han, Y. Zhang, J. Kang, J. Tang, and Y. Zhang, "Chemiluminescence determination of terbutaline sulfate in bovine urine and pharmaceutical preparations based on enhancement of the 2-phenyl-4, 5-di (2-furyl) imidazole-potassium ferricyanide system," Journal of Pharmaceutical and Biomedical Analysis, vol. 58, no. 1, pp. 141-145, 2012.

[10] B. Liu, Y. He, C. Duan, N. Li, and H. Cui, "Platinum nanoparticle-catalyzed lucigenin-hydrazine chemiluminescence," Journal of Photochemistry and Photobiology A: Chemistry, vol. 217, no. 1, pp. 62-67, 2011.

[11] S. A. Barker, A. R. Long, and C. R. Short, "Isolation of drug residues from tissues by solid phase dispersion," Journal of Chromatography, vol. 475, pp. 353-3361, 1989.

[12] S. A. Barker, "Matrix solid phase dispersion (MSPD)," Journal of Biochemical and Biophysical Methods, vol. 70, no. 2, pp. 151-162, 2007.

[13] S. Bogialli and A. Di Corcia, "Matrix solid-phase dispersion as a valuable tool for extracting contaminants from foodstuffs," Journal of Biochemical and Biophysical Methods, vol. 70, no. 2, pp. 163-179, 2007.

[14] V. D. Papadopoulos, G. N. Beligiannis, and D. G. Hela, "Combining experimental design and artificial neural networks for the determination of chlorinated compounds in fish using matrix solid-phase dispersion," Applied Soft Computing Journal, vol. 11, no. 8, pp. 5155-5164, 2011.

[15] M. Y. Piñero, M. Fuenmayor, L. Arce, R. Bauza, and M. Vílchez, "A simple sample treatment for the determination of enrofloxacin and ciprofloxacin in raw goat milk," Microchemical Journal, vol. 110, pp. 533-537, 2013.

[16] A. Navalón, R. Blanc, L. Reyes, N. Navas, and J. L. Vílchez, "Determination of the antibacterial enrofloxacin by differentialpulse adsorptive stripping voltammetry," Analytica Chimica Acta, vol. 454, no. 1, pp. 83-91, 2002. 

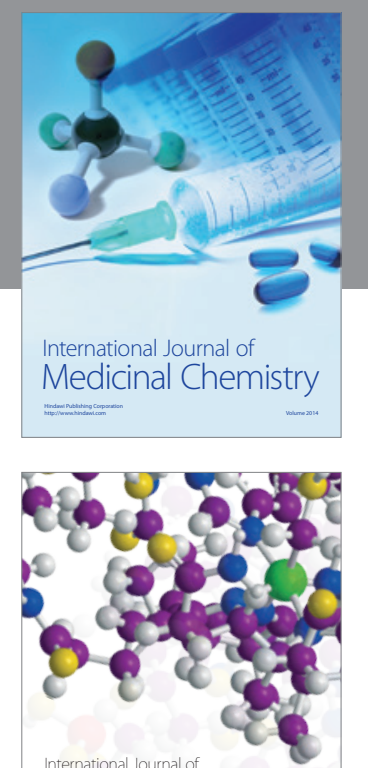

\section{Carbohydrate} Chemistry

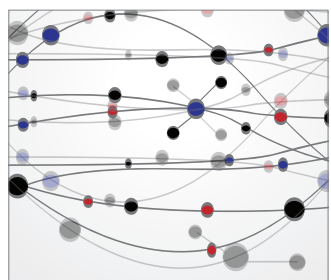

The Scientific World Journal
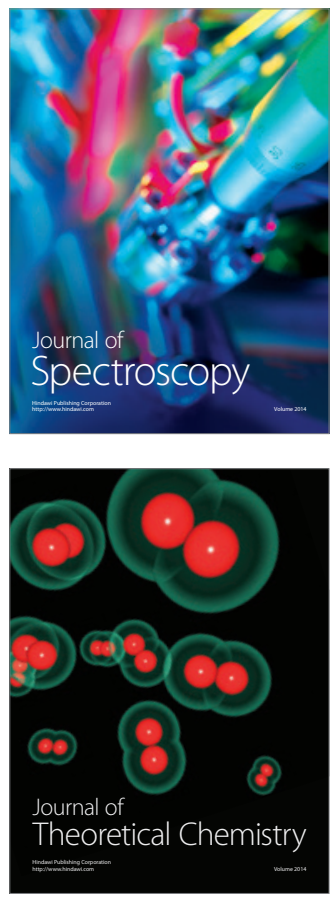
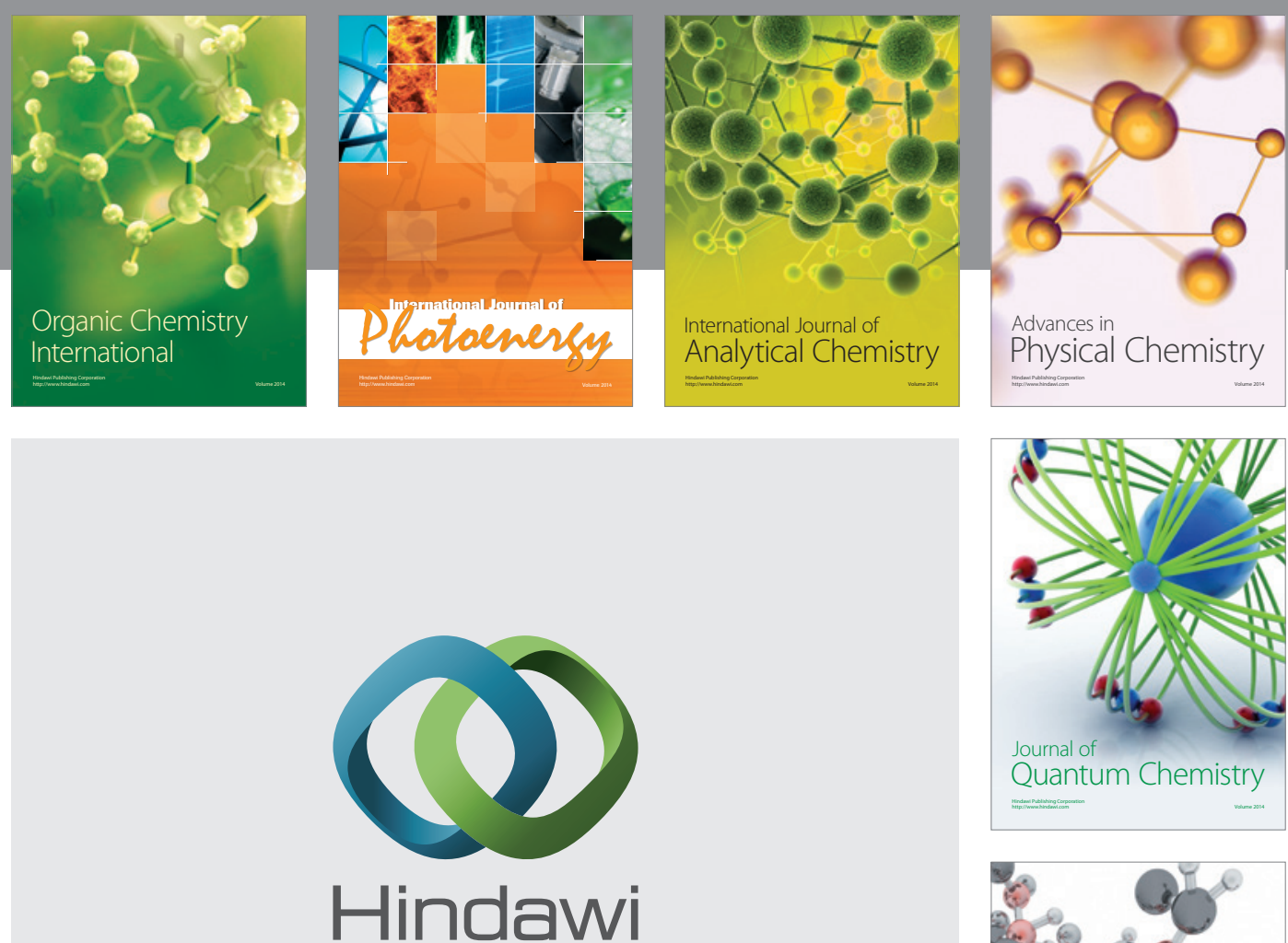

Submit your manuscripts at

http://www.hindawi.com

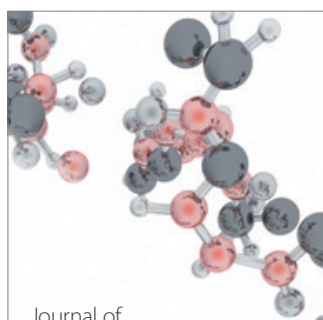

Analytical Methods

in Chemistry

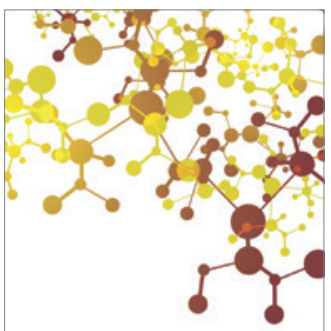

Journal of

Applied Chemistry

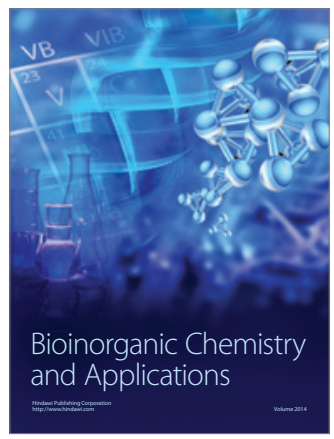

Inorganic Chemistry
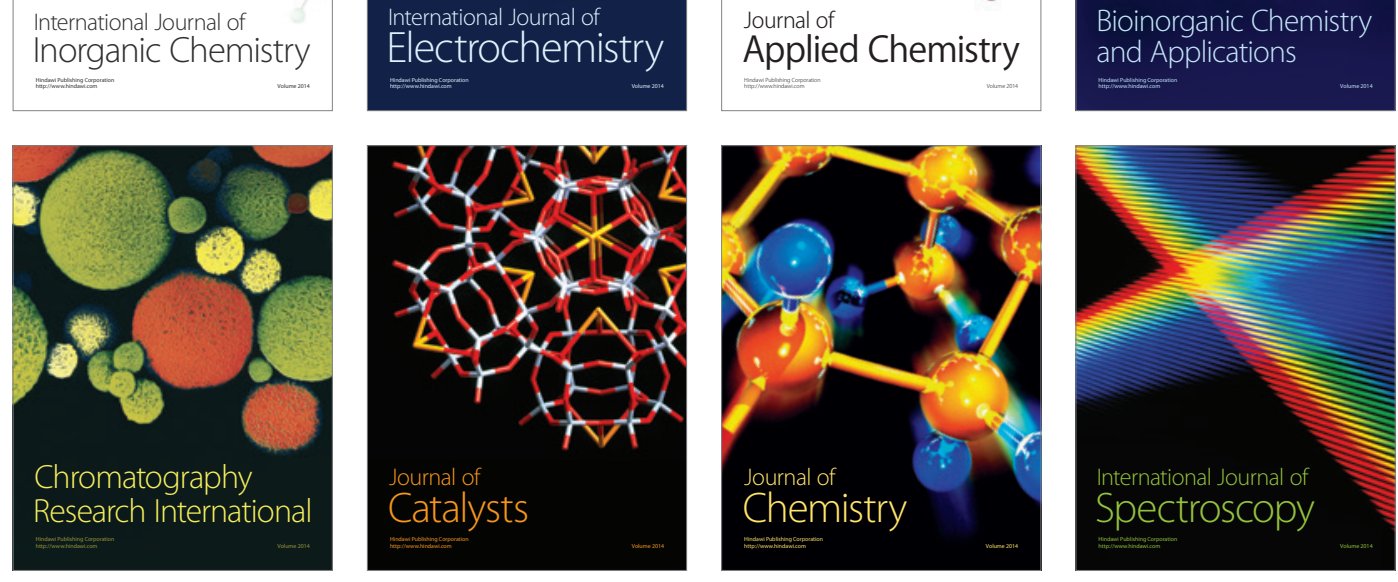